\title{
Clinical diagnosis and treatment of scabies, a neglected tropical disease
}

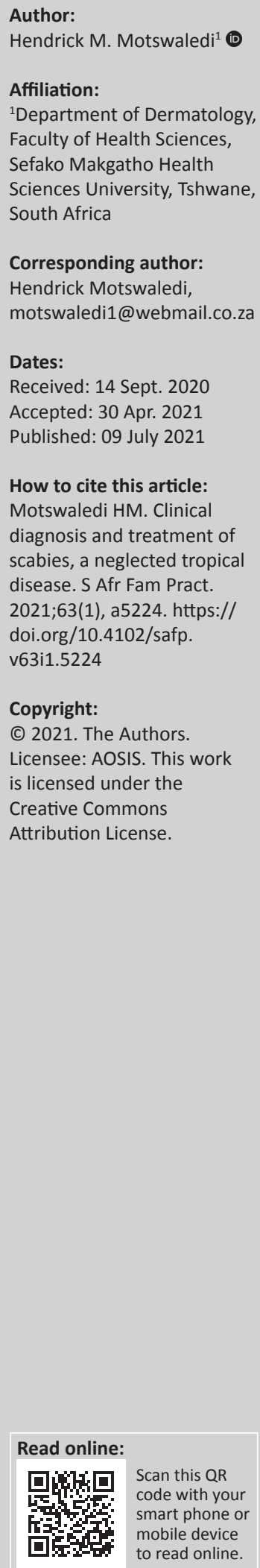

Scabies is a parasitic infestation of the skin caused by the mite Sarcoptes scabiei var. hominis. It is common in tropical areas, including the sub-tropical areas of Southern Africa. Predisposing factors are overcrowding, poor personal hygiene, low socio-economic standards and impaired host immunity. Although it can occur at any age, scabies is commonly seen in children and young adults. It is not a fatal disease; however, it can cause severe morbidity and poor quality of life. Scabies can complicate with pyoderma which may result in post-streptococcal glomerulonephritis. There are two clinical variants, classic scabies and the much rarer crusted scabies (Norwegian scabies).

Keywords: scabies, Sarcoptes scabiei; permethrin; ivermectin; non-fatal disease; pyoderma.

\section{Classic scabies}

The term 'scabies' is derived from the Latin word 'scabere' meaning to scratch. ${ }^{1}$ Scabies is a parasitic infestation caused by the mite Sarcoptes scabiei var. hominis. ${ }^{2}$ This mite is a host specific, obligate parasite in humans.,

In 2013, scabies was recognised by the World Health Organization (WHO) as one of the neglected tropical diseases of public health importance. ${ }^{5,6}$ It is estimated to affect more than 130 million people globally at any time..$^{5,6}$

\section{Epidemiology}

It is a worldwide problem affecting all races and socio-economic groups. ${ }^{3}$ It occurs commonly in children, but can occur at any age. ${ }^{2}$ Several members of a family can be simultaneously affected as the mites are transmitted by close personal contact. ${ }^{1}$

It is common in poor communities because of overcrowded living conditions, for example, in old age homes and prisons as well as in homeless and displaced children. ${ }^{7}$ In developed countries, it can occur as small epidemics in situations like war and during natural disasters. ${ }^{1,2}$

Once the human skin is infested, female mites burrow into the stratum corneum of the epidermis. They live for 4 to 6 weeks and produce two to four eggs per day, deposited into the burrowed tunnel. Larvae hatch 4 days later and develop into adult mites after 10 to 14 days. ${ }^{8}$ Mites can live for up to 3 days without a human host and there is evidence that fomites like clothing and linen can spread classic scabies. ${ }^{9}$

\section{Clinical presentation}

Pathognomonic lesions are burrows that are caused by the mite as it penetrates the skin. The mite produces a lytic secretion which dissolves the host tissue and allows the mite to propel itself forward in the stratum corneum. ${ }^{1,2,3}$ Clinical manifestations of scabies typically develop 3-4 weeks after infestation. Clinical features are mainly because of an immune response to the presence of mites in the skin. ${ }^{1,4}$ It should be noted that the development of an immune response does not eliminate the disease and does not confer immunity against reinfestation. ${ }^{1}$

Scabies is characterised by intense pruritus, often worse nocturnally. ${ }^{1,3}$ Pruritus is the result of a hypersensitivity reaction to components of the saliva, ova and faecal material of the mites. ${ }^{10}$

Cutaneous lesions are inflammatory papules, vesicles, indurated nodules and pustules. Scabies can mimic many other skin diseases such as atopic eczema, seborrhoeic dermatitis, disseminated varicella and many others. 
Common areas for scabies lesions are the flexor aspect of wrists, dorsal aspects of hands (Figure 1), finger web spaces, palms, sides of fingers, feet, axillae, umbilicus and intergluteal cleft (Figure 2). 1,2,3 Male genitalia and areolae in females are commonly affected.

In neonates, scabies may be difficult to diagnose as the clinical picture is different to that of older children and adults. In this age group, the eruption turns to be generalised, including head, neck, face, palms and soles with early tendency to pustule formation. ${ }^{11}$

\section{Complications}

Complications of scabies include eczematisation, secondary bacterial infections and post-streptococcal glomerulonephritis. Long-standing lesions can have secondary changes like eczematisation that is widespread and resembles chronic eczema. Scratching and excoriations cause breaks in the epidermis, serving as entry points for pathogenic bacteria. Secondary infection of scabies lesions may result in folliculitis, impetigo, ecthyma and abscesses. If secondary infection with $\beta$-haemolytic Streptococci or nephritogenic strains of Streptococcus pyogenes occurs, this may result in poststreptococcal glomerulonephritis., ${ }^{5,10,12}$ This is presumably by way of molecular mimicry. Studies have shown that epidemics of scabies have resulted in increased incidence of post-streptococcal glomerulonephritis in some populations. ${ }^{13}$

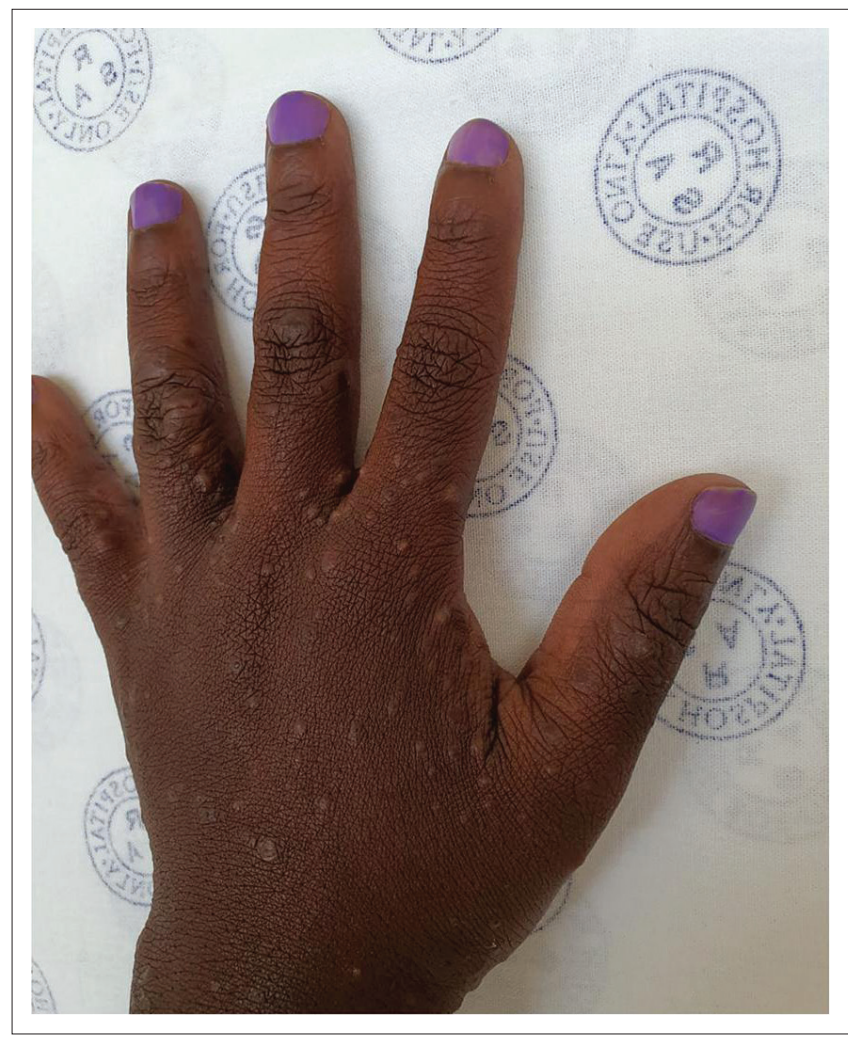

FIGURE 1: Scabies papules on the dorsum of the hand, note the involvement of the web spaces.

\section{Diagnosis}

Scabies is confirmed by detecting the mites, ova and faecal matter with microscopy. A skin scraping of a burrow is done with a scalpel blade, and the material is put on a glass slide; $10 \%$ potassium hydroxide $(\mathrm{KOH})$ or mineral oil is added, and the slide is examined microscopically (Figure 3). ${ }^{1,2,3,4}$

This, however, is not always possible, especially in classic scabies, where the mite burden is lower. In this situation, it is acceptable to presume the diagnosis based on history and clinical findings.

Dermoscopy can also be performed using a hand-held dermatoscope with x10 magnification, but this has a low specificity. Skin biopsy is only done for difficult cases and to rule out other skin diseases like chronic eczema and psoriasis.

\section{Treatment}

Treatment of scabies is aimed at elimination of the mites, treatment of symptoms and signs, as well as treatment of secondary bacterial infection if present.

\section{Prevention of spread}

Close house-hold and family contacts must all be treated to help prevent the spread of the disease and also to prevent reinfection.

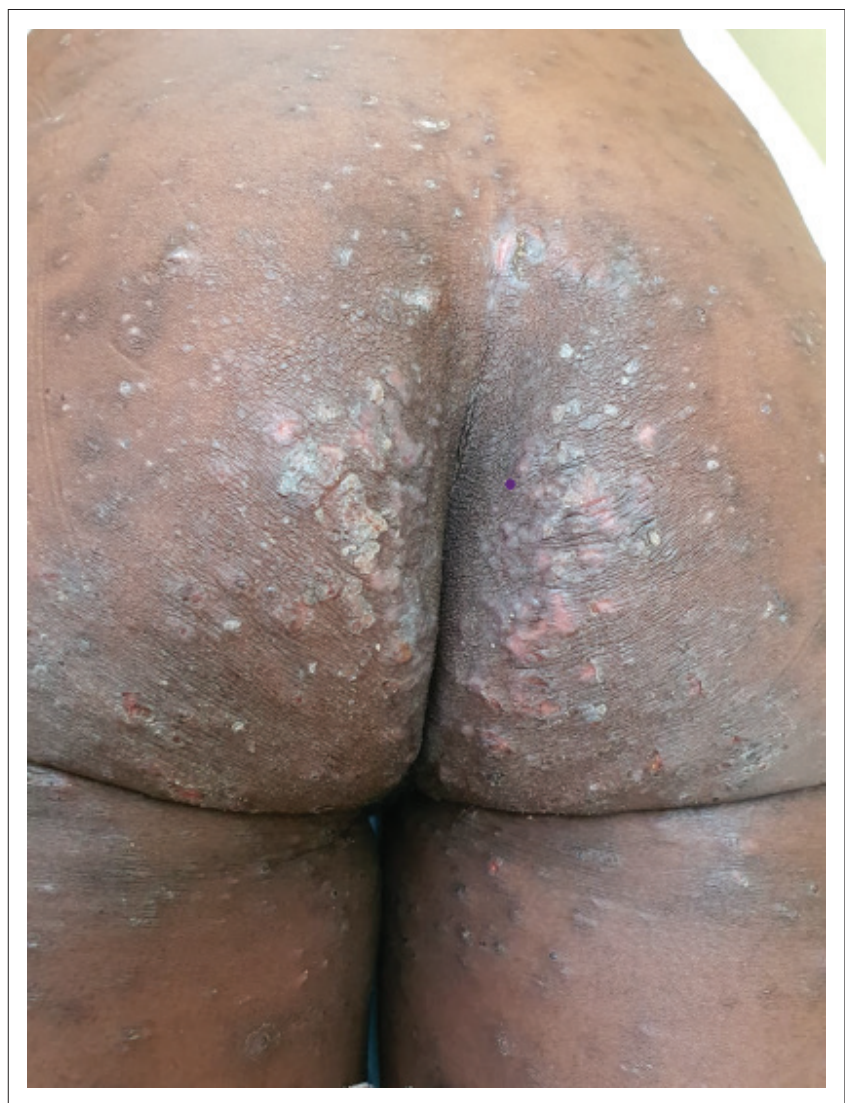

FIGURE 2: Eczematisation of scabies on thighs, buttocks and intergluteal cleft. Note the excoriations and crusting. 
Bed linen, towels and clothing must be soaked in boiling water, and washed and dried in the sun to eliminate the mites.

\section{Topical treatment}

Scabicidal soaps like Tetmosol soap ${ }^{\circledast}$ (which contains monosulfirum 5\%) should be used for bathing. Permethrin $5 \%$ lotion or cream is the first-line treatment of scabies in many countries. Permethrin acts on the nerve cell membranes of the mites to disrupt the sodium channel current by which the polarisation of the membrane is regulated. This results in delayed polarisation and subsequent paralysis and death of the mites.

Permethrin 5\% is applied once at night and washed off in the morning. Re-application is always recommended, because mite eggs hatch 2-6 days later and can result in disease recurrence. It is effective, has low toxicity and is less irritant to the skin than benzyl benzoate and therefore suitable for use in children. ${ }^{10,14,15}$ Its safety in pregnancy and lactation has not been established. In addition to concerns over toxicity of these topical compounds, parasite resistance seems to be increasing. ${ }^{9}$

Permethrin is not always available in primary healthcare setting in South Africa. Benzyl benzoate is recommended on day 1 , day 2 ( 2 consecutive days) and day 7 . In paediatrics, a $10 \%$ formulation is available as opposed to the $25 \%$ adult formulation that can irritate the immature skin more.

Benzyl benzoate is a strong skin irritant which may cause a burning sensation, resulting in reduced compliance. Children may not tolerate it. A $10 \%$ sulphur mixed with petrolatum base or emulsifying ointment can be used and is well tolerated by children. Sulphur is messy and malodorous

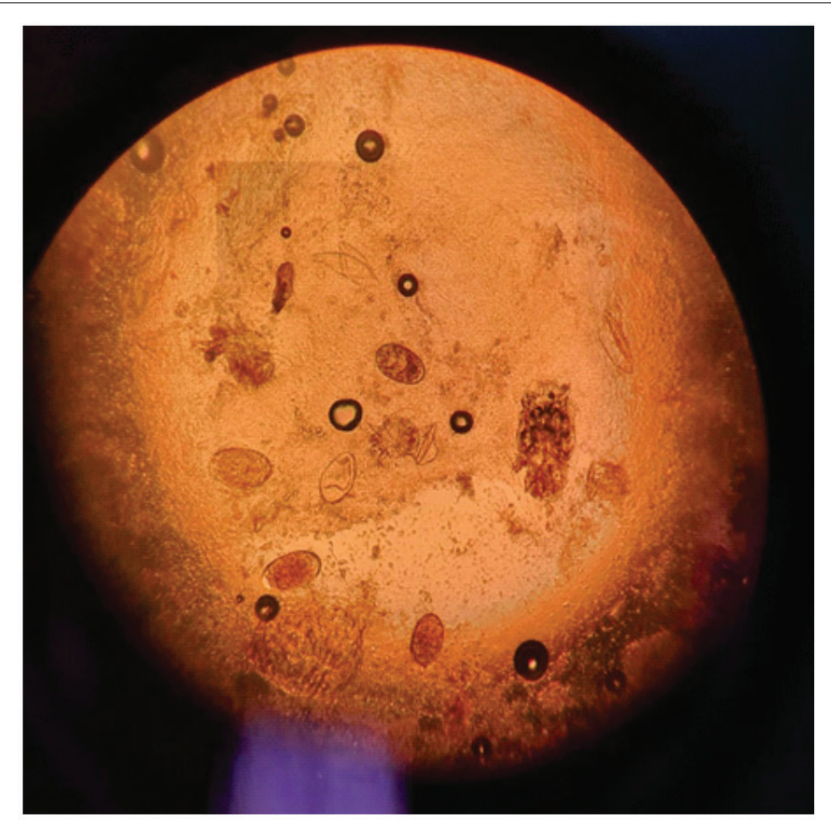

FIGURE 3: Ova of Sarcoptes scabiei on potassium hydroxide preparation. and can stain clothes and linen, but its efficacy in treating scabies is high. When applying topical agents, specific attention should be paid to the finger nails, toe nails, postauricular areas, groins, interdigital spaces, natal cleft and axillary regions. Scabies patients can experience itch up to a month after successful treatment. Second-generation antihistamines may be necessary for a month to alleviate the itch. Adjuvant treatment like chlorhexidine antiseptics may be necessary to prevent secondary bacterial infection.

\section{Crusted scabies (Norwegian scabies)}

Crusted scabies, formerly called Norwegian scabies, was first described in 1848 in leprosy patients in Norway. ${ }^{1,4}$ It is a type of scabies in which a large number of mites are present in the skin, and thus, the host's response gets overwhelmed, allowing the mites to multiply. There are millions of mites in a patient with crusted scabies. ${ }^{16}$

Crusted scabies often occurs in patients who are immunocompromised, for example, patients infected with HIV, human T-cell lymphotropic virus-1 or leukaemia, neurologically impaired patients who cannot scratch, for example, paraplegics and quadriplegics, as well as in leprosy patients with neuropathies. ${ }^{16}$ It may also occur in patients with mental disorders like senile dementia, Down's syndrome ${ }^{17}$ and patients with severe nutritional deficiencies. ${ }^{1,3,4}$ It is rarely seen in patients with healthy immune systems. ${ }^{10,12,16}$

In crusted scabies, thick hyperkeratotic crusts occur on the skin with erythroderma (Figures 4 and 5). This clinical picture can resemble psoriasis. ${ }^{17}$ The crusts carry millions of these mites and may shed them off to the patient's environment, thereby infecting others. Unlike in classic scabies, in crusted scabies, a skin biopsy is almost always

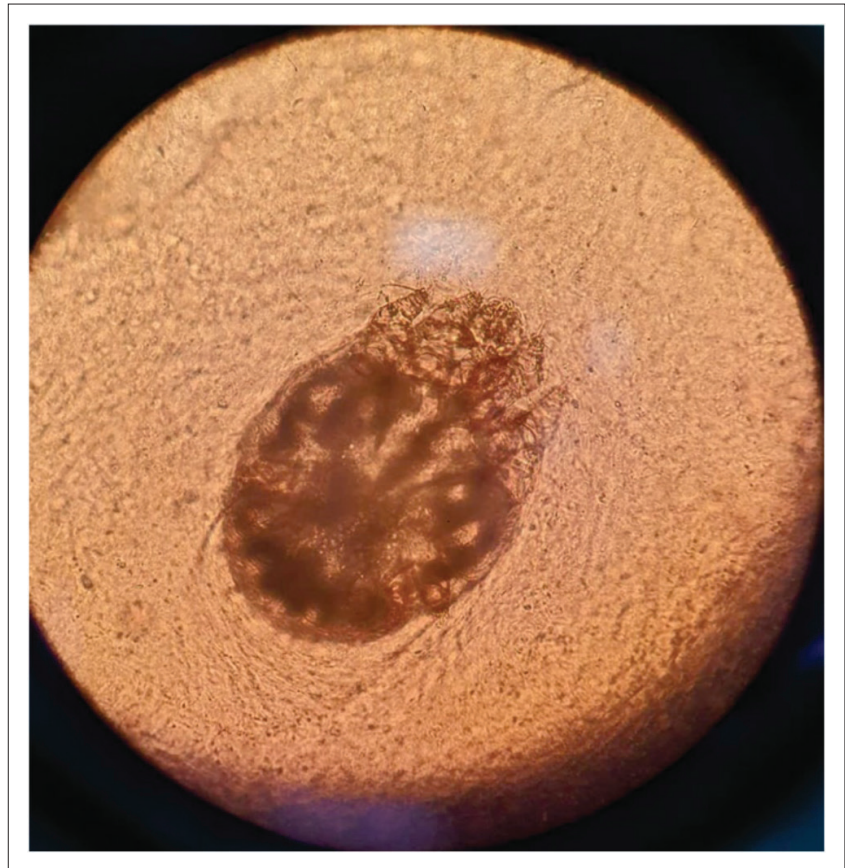

FIGURE 4: Sarcoptes scabiei mite on potassium hydroxide preparation. 


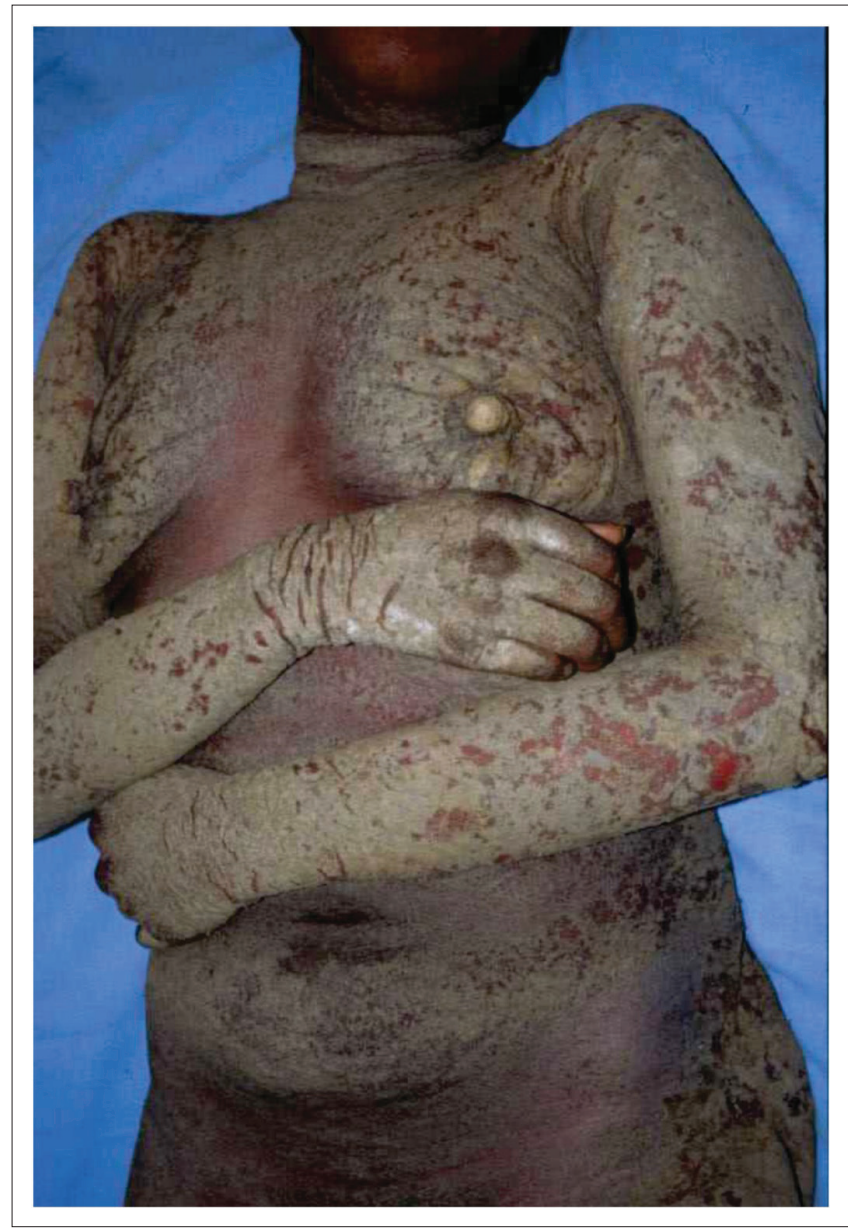

FIGURE 5: Crusted scabies in an immunocompromised patient.

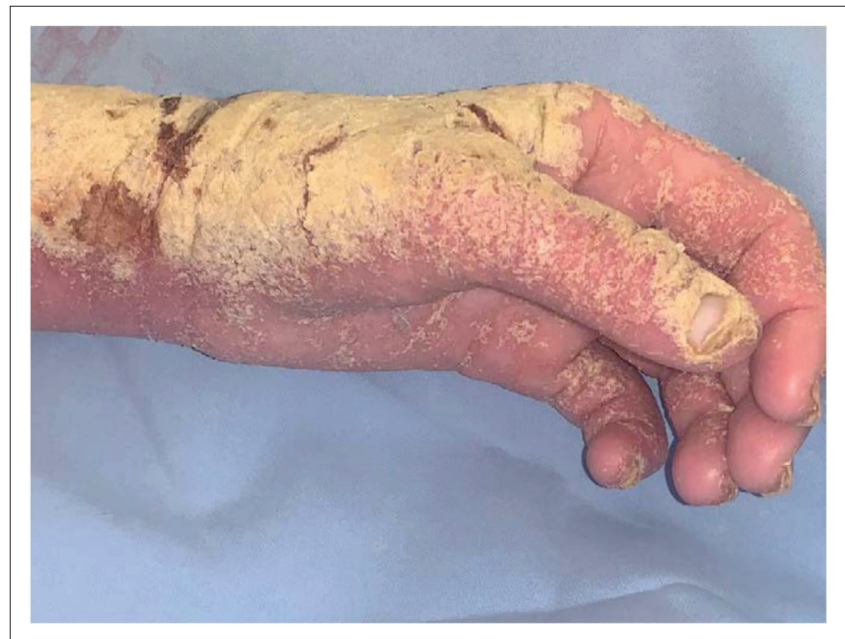

FIGURE 6: Crusted scabies in an albino patient, note the subungual hyperkeratosis.

diagnostic as mites and ova can be easily visualised in the thickened stratum corneum (Figure 6). Peripheral eosinophilia and immunoglobulin E levels are usually raised in patients with crusted scabies. . $^{8,10,18}$

Treatment for crusted scabies is the same as for ordinary scabies, but multiple applications of scabicides are required (Figure 7). Ideally, patient with crusted scabies must be admitted in hospital isolation ward to treat underlying conditions as well. Ivermectin if available can be used in recalcitrant cases.

Oral ivermectin, a macrocyclic lactone structurally similar to the macrolide antibiotics but devoid of antibacterial activity, has a good safety profile ${ }^{19,20}$ and has revolutionised treatment of ectoparasites. ${ }^{21,22}$ The efficacy of oral ivermectin

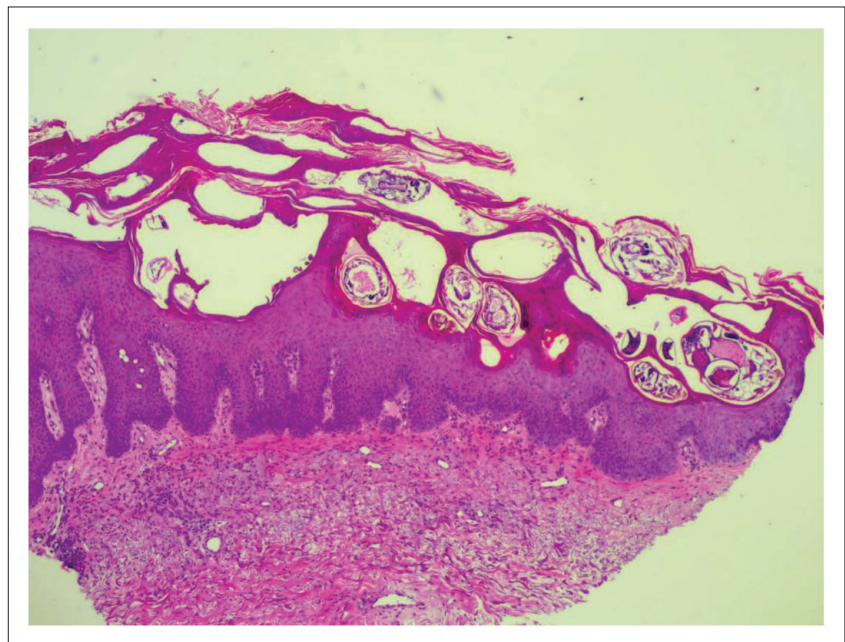

FIGURE 7: Honeycombed stratum corneum with scabies mites and ova (magnification $\times 40$ ).

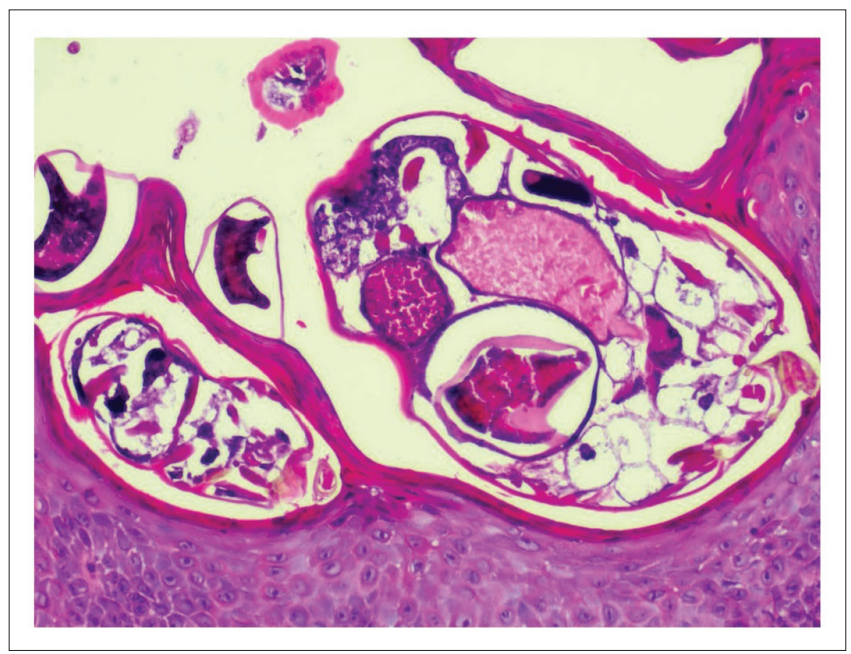

FIGURE 8: Higher magnification showing scabies mites (magnification x100).

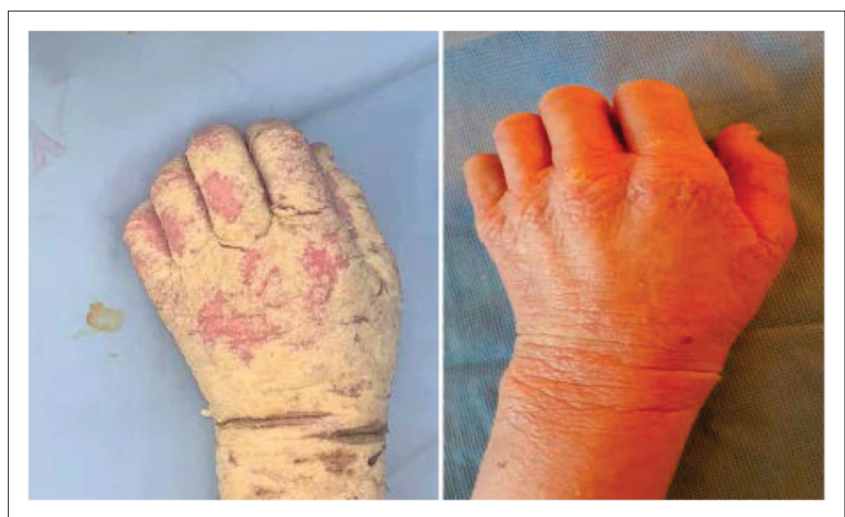

FIGURE 9: Crusted scabies before and after treatment. This patient was treated with permethrin $5 \%$ lotion, two applications a week apart. 
is equivalent to or better than that of topically applied lindane ${ }^{23}$ and benzyl benzoate. ${ }^{24}$ In one study, two doses of ivermectin were found to be as effective as a single application of permethrin. ${ }^{25}$ Oral ivermectin can also eliminate intestinal parasites and therefore can benefit patients who are polyparasitised with enteroparasites and ectoparasites. ${ }^{19,26}$

Oral ivermectin in single doses of $200 \mu \mathrm{g} / \mathrm{kg}$, with a second dose given after 10 days, has been shown to be very effective in a number of studies. ${ }^{26,27}$ Ivermectin is very useful in controlling the outbreaks of scabies in closed communities such as prisons where it is easy to administer a single dose under supervision and avoid problems of compliance and inadequate application associated with topical therapy. ${ }^{19}$

Ivermectin is also useful in treating patients with scabies and HIV and other immunocompromised patients, who may be difficult to cure as they require several applications of different topical agents or combinations of therapy over a period of weeks. ${ }^{28}$

In many African countries where parasitic infestations like scabies, onchocerciasis and filariasis are a major problem, patients are treated with intramuscular or oral ivermectin. ${ }^{29}$ In South Africa, currently injectable ivermectin is only registered for veterinary use. ${ }^{30}$

\section{Conclusion}

Scabies is a fairly common skin disease. Although it is not a fatal disease, it may result in severe morbidity and poor quality of life. Clinicians must acquaint themselves with its diagnosis and treatment.

\section{Acknowledgements}

The author would like to thank Dr G. Shikwambana-Ntlemo and her team from the Department of Microbiology for the nice potassium hydroxide $(\mathrm{KOH})$ preparations from our patient with crusted scabies. The author would also like to thank Dr I. Daba of the Department of Anatomical Pathology for the haematoxylin and eosin preparation of the skin biopsy.

\section{Competing interests}

The author declares that he has no financial or personal relationships that may have inappropriately influenced him in writing this article.

\section{Authors' contributions}

M.H.M. is the sole author of this manuscript.

\section{Ethical considerations}

Permission was obtained from patients whose clinical material has been used in this article. This article followed all ethical standards for research without direct contact with human or animal subjects.

\section{Funding information}

This research received no specific grant from any funding agency in the public, commercial or not-for-profit sectors.

\section{Data availability}

Data sharing is not applicable to this article as no new data were created or analysed in this study.

\section{Disclaimer}

The views and opinions expressed in this article are those of the author and do not necessarily reflect the official policy or position of any affiliated agency of the author.

\section{References}

1. Prediville JS. Scabies and lice. In: Irvine AD, Hoeger PH, Yan AC, editors. Harper's textbook of pediatric dermatology. 3rd ed. Oxford: Wiley-Blackwell; 2011; p. 72.1-72.16

2. Burns DA. Diseases caused by arthropods and other noxious animals. In Champion RH, Burton JL, Burns DA, Breathnach SM, editors. Rook/Wilkinson/ Ebling textbook of dermatology. 6th ed. Oxford: Blackwell Science; 1998; p. $1423-1481$.

3. Burkhart CN, Burkhart CG, Morrel DS. Infestations. In Bolognia JL, Jorizzo JL, Schaffer JV, editors. Dermatology. 3rd ed. New York: Elsvier Saunders; 2012; p. 1423-1434.

4. Habif TP. Infestations and bites. In clinical dermatology, a color guide to diagnosis and therapy. 6th ed. China: Elsevier; 2016; p. 577-634.

5. Currie BJ. Scabies and global control of neglected tropical diseases. N Engl J Med. 2015;373(24):2371-2372. https://doi.org/10.1056/NEJMe1511805

6. Engelman D, Steer AC. Control strategies for scabies. Trop Med Infect Dis. 2018;3(98)1-11. https://doi.org/10.3390/tropicalmed3030098

7. Terry BC, Kanja F, Sahr F, et al. Sarcoptes scabiei infection among children in a displacement camp in Sierra Leone. Public Health. 2001;155(3):208-211. https:// doi.org/10.1016/S0033-3506(01)00445-0

8. Arlian LG. Biology, host relations, and epidemiology of sarcoptes scabiei. Ann Rev Entomol. 1989;34:139-161. https://doi.org/10.1146/annurev.en.34.010189. 001035

9. Fawcett RS. Ivermectin use in scabies. Am Fam Physician. 2003;68(6):1089-1092.

10. Heukelbach J, Feldmeier H. Scabies. Lancet. 2006;367(9524):1767-1774. https:// doi.org/10.1016/S0140-6736(06)68772-2

11. Burns BR, Lampe RM, Hansen GH. Neonatal scabies. Am J Dis Child. 1979;133(10):1031-1034. https://doi.org/10.1001/archpedi.1979.02130100055012

12. Gladstone HB, Darmstadt GL. Crusted scabies in an immunocompetent child Treatment with ivermectin. Pediatr Dermatol. 2000;17(2):144-148. https://doi. org/10.1046/j.1525-1470.2000.01736.x

13. Reid HF, Birju B, Holder $Y$, et al. Epidemic scabies in four Carribbean islands, 1981-1988. Trans R Soc Trop Med Hyg. 1990;84(2):298-300. https://doi. org/10.1016/0035-9203(90)90296-Q

14. McCarthy JS, Kemp DJ, Walton SF, et al. Scabies: More than just an irritation. Postgrad Med J. 2004;80(945):382-387. https://doi.org/10.1136/pgmj.2003. 014563

15. Quanterman MJ, Lesher JL Jr. Neonatal scabies treated with Permethrin $5 \%$ cream. Pediatr Dermatol. 1994;11(3):264-266. https://doi.org/10.1111/j.15251470.1994.tb00600.x

16. Roberts $\mathrm{L}$, Huffam SE, Walton $S F$, et al. Crusted Scabies. Clinical and immunological findings in seventy-eight patients and a review of the literature. J Infect. 2005;50(5):375-381. https://doi.org/10.1016/j.jinf.2004.08.033

17. Gach JE, Heagerty A. Crusted scabies looking like psoriasis. Lancet. 2000;356(9230): 650. https://doi.org/10.1016/S0140-6736(00)02608-8

18. Arlian LG, Morgan MS, Estes SA, et al. Circulating IgE in patients with ordinary and crusted scabies. J Med Entomol. 2004;41(1):74-77. https://doi.org/10.1603/00222585-41.1.74

19. Leppard B, Naburi AE. The use of Ivermectin in controlling an outbreak of scabies in a prison. Br J Dermatol. 2000;143(3):520-523. https://doi.org/10.1111/j.1365 2133.2000.03704.x

20. Dourmishev AL, Dourmishev LA, Schwartz RA. Ivermectin: Pharmacology and application in Dermatology. Int J Dermatol. 2005;44(12):981-988. https://doi org/10.1111/j.1365-4632.2004.02253.x

21. Burkhart KM, Burkhart CN, Burkhart CG. Our scabies treatment is archaic, but ivermectin has arrived. Int J Dermatol. 1998; 37(1):76-79. https://doi.org/ 10.1046/j.1365-4362.1998.00404.x

22. Del Giudice P, Marty P, Gari-Toussaint M, et al. Ivermectin in elderly patients. Arch Dermatol. 1999;135(3):351-352. 
23. Madan V, Jaskiran K, Gupta U, et al. Oral ivermectin in scabies patients: A comparison with $1 \%$ topical lindane lotion. J Dermatol. 2001;28:481-484. https:// doi.org/10.1111/j.1346-8138.2001.tb00015.x

24. Sule HM, Thacher TD. Comparison of ivermectin and benzyl benzoate lotion for scabies in Nigerian patients. Am J Trop Med Hyg. 2007;76(2):392-395. https://doi. org/10.4269/ajtmh.2007.76.392

25. Usha V, Nair TV. A comparative study of oral ivermectin and topical permethrin cream in the treatment of scabies. J Am Acad Dermatol. 2000;42(2):236-240. https://doi.org/10.1016/S0190-9622(00)90131-2

26. Heukelbach J, Winter B, Wilcke T, et al. Selective mass treatment with ivermectin to control intestinal helminthiases and parasitic skin disease in a severely affected population. Bull WHO. 2004;82:563-571.
27. Tucker WFG. Scabies. In Lebwohl MG, Heyman WR, Berth-ones J, Coulson I, editors. Treatment of skin disease: Comprehensive therapeutic strategies. 2nd ed. China: Mosby Elsevier; 2007; 595-597.

28. Meinking TL, Taplin D, Hermida JL, et al. The treatment of scabies with Ivermectin. N Engl J Med. 1995;333:26-30. https://doi.org/10.1056/NEJM 199507063330105

29. Motswaledi MH. Common dermatological conditions in the HIV patient. S Afr Fam Pract. 2019; 61(1):17-20. https://doi.org/10.4102/safp.v61i1.5049

30. Motswaledi $\mathrm{MH}$, Visser W. The spectrum of HIV-associated infective and inflammatory dermatoses in pigmented skin. Dermatol Clin. 2014;32(2):211-225. https://doi.org/10.1016/j.det.2013.12.006 